Research article

\title{
Morphological types of breast cancer in family members and multiple primary tumours: is morphology genetically determined?
}

\author{
Kari Hemminki and Charlotta Granström \\ Department of Biosciences at Novum, Karolinska Institute, Huddinge, Sweden
}

Correspondence: Kari Hemminki, CNT Novum, 141 57, Sweden. Tel: +46 8 6089243; fax: +46 8 6081501; e-mail: kari.hemminki@cnt.ki.se

Received: 17 January 2002

Accepted: 22 March 2002

Published: 18 April 2002
Breast Cancer Res 2002, 4:R7

(C) 2002 Hemminki and Granström, licensee BioMed Central Ltd (Print ISSN 1465-5411; Online ISSN 1465-542X)

\begin{abstract}
Background: We conducted the present study to determine whether breast cancer morphology is genetically determined.

Methods: Using the nationwide Swedish Family Cancer Database, which includes data on 10.2 million individuals and over 25,000 morphology-specific breast cancers, we followed morphological types in familial cancers between mothers and daughters and between sisters. Additionally, we recorded morphological data in women who presented with two primary breast cancers and in those who presented with an invasive and in situ breast cancer. We used kappa statistics to examine the association between genetics and morphology. A kappa value of 0 indicates that the process is random and a value of 1 indicates that it is completely determined (i.e. genetic); values between 0.40 and 0.60 are considered to indicate a moderately determined process.

Results: The study sample included a total of 25,730 first and 3394 second invasive breast cancers, and 2990 in situ breast cancers. Ductal, lobular, tubuloductal and comedo were the most common invasive types. We identified 164 mother-daughter pairs with breast cancer of a defined morphology, yielding a low kappa value of 0.08 . Among 100 sister pairs the kappa value was 0.002 . In individuals with two primary breast cancers the kappa values were 0.22 and 0.01 for two invasive and in situinvasive pairs, respectively. However, for a tumour with a subsequent tumour detected in the contralateral breast less than 1 year later the kappa value was 0.47 .

Conclusion: The data suggest that breast cancer morphology is not genetically determined. However, because of mixed morphologies and the overwhelming prevalence of ductal morphology, the results for rare morphologies should be interpreted with caution.
\end{abstract}

Keywords: ductal cancer, familial cancer, genetic effect, lobular cancer, second primary

\section{Introduction}

Tumours of the breast are believed to arise from terminal ductal lobular units and comprise two common morphological types: ductal and lobular neoplasia [1]. Rarer morphological types include tubuloductal, comedo, medullary, mucinous and Paget types [2]. Morphological type has implications for treatment and prognosis, and it would be of interest to determine whether morphological type is genetically determined.

Breast tumours often present with mixed morphological types, suggesting that in such cases a single genetic background can give rise to tumours of multiple morphologies. It is also known that lobular in situ cancers may give

$I C D=$ International Classification of Diseases 
rise to ductal invasive cancers $[2,3]$. Very limited data are available on morphological types in familial and heritable breast cancer. The only consistent morphological features in breast cancers associated with mutations in the BRCA1 and BRCA2 genes are the lower frequencies of lobular morphology as compared with the frequencies in $B R C A 1 / 2$-unrelated familial breast cancers $[4,5]$. BRCA1related tumours exhibit a small excess of medullary-like morphology. BRCA1/2-related breast cancers also tend to have ductal or lobular in situ histology less frequently than do all breast cancers combined [5]. Familial breast cancers that are unrelated to $B R C A 1 / 2$ have not shown any significant morphological difference from all breast cancers combined [4]. On the basis of earlier small studies, it was assumed that mutations in the E-cadherin gene are only present in lobular breast cancer; this was not confirmed in a recent larger study, however, which identified mutations in the E-cadherin gene in ductal cancer also [6].

In the present study we used the nationwide Swedish Family Cancer Database to examine the morphological types of breast cancer in family members and in individuals with two primary tumours [7]. The Database was updated in 2001 to include over 10 million individuals and over 1 million registered tumours, retrieved from the Swedish Cancer Registry for the years 1958-1998. It offers unique possibilities for reliable estimation of familial risk because the data on familial relations and cancers were obtained from registered sources with practically complete coverage. The Swedish Cancer Registry has used the International Classification of Diseases (ICD) coding system ICD-O-2 since 1993. Thus, the specific morphological classification covers only 6 years, but because of its nationwide coverage a large number of breast cancer patients are included.

We conducted the present study in order to determine whether morphological type defines a discrete genetic background.

\section{Patients and methods}

The Swedish Family Cancer Database was initially created during the mid 1990s by linking an administrative family register on all Swedish families to the Swedish Cancer Registry [7-9]. For each child there are data on both parents at the time of birth. Each person has been assigned a unique identification number (which is different from the national identification number - the 'personal number'); this allows construction of families, for example, through the mother. The Database includes data for all persons born in Sweden after 1931, along with data for their biological parents, totalling over 10.2 million individuals. It was updated at the start of the year 2001 to include cancers from the nationwide Swedish Cancer Registry for the years 1958-1998. The Database is organized into 3.2 million families (parents and offspring).
The completeness of cancer registration during the 1970 s has been estimated at over $95 \%$, and is now considered to be close to $100 \%$. The percentage of cytologically or histologically verified breast cancer cases is close to $100 \%$ [10]. The Swedish Family Cancer Database has incomplete linkage from deceased offspring to parents, particularly among those born between 1932 and 1940. Out of a total of 7.0 million offspring, 216,000 had died by the end of follow up (31 December 1998). Parental information was missing for 15,000 deceased offspring who had a diagnosis of cancer ( $9.9 \%$ of all cancers in offspring). This deficit is unlikely to have any significant impact on the findings of the present study.

The Swedish Cancer Registry is based on compulsory notification of cases [10]. A four-digit diagnostic code, in accordance with the 7th revision of the ICD, was used until the year 1992; thereafter, the ICD-O-2 coding system was employed. In cases of multiple morphological types, the notifications considered the most common morphology. Among first and second breast cancers, and in situ and invasive cancers, all cases were included; however, the analysis considered whether second cancers occurred in the same breast or in the contralateral one, and the time interval between diagnoses.

Family history information was collected for all first-degree relatives (parents, siblings and children), but only mother-daughter and sister-sister relationships were considered in the present study. In a small number of families three or more sisters were affected, but they were not included in the present analysis.

Statistical analysis was based on kappa statistics as a measure of agreement between morphologies; kappa values are calculated using the following equation $[11,12]$.

Kappa $=\frac{\text { observed number of cases }- \text { expected number of cases }}{1-\text { expected number of cases }}$

Kappa can take values between -1 and 1; 0 indicates complete chance occurrence, and -1 or 1 indicates a process that is completely determined. Values between 0.40 and 0.60 are considered moderately determined. For simplicity, in the present report we present only positive values of kappa by deleting the minus sign. The kappa values are unweighted, but all findings were also tested using the weighted kappa test, with unaltered results [11]. Some tests were also done on selected morphological types.

Use of the Swedish Family Cancer Database was approved by the Ethics Committee of the Karolinska Institute, south. 
Table 1

\begin{tabular}{|c|c|c|c|c|c|c|}
\hline \multirow[b]{2}{*}{ Morphology } & \multicolumn{2}{|c|}{ 1st invasive } & \multicolumn{2}{|c|}{ 2nd invasive } & \multicolumn{2}{|c|}{ In situ } \\
\hline & $n$ & $\%$ & $n$ & $\%$ & $n$ & $\%$ \\
\hline Ductal & 14,187 & 66.2 & 1679 & 60.9 & 1834 & 69.9 \\
\hline Lobular & 2936 & 13.7 & 531 & 19.2 & 324 & 12.4 \\
\hline Tubuloductal/tubular & 1915 & 8.9 & 232 & 8.4 & 2 & 0.1 \\
\hline Comedo & 1190 & 5.6 & 133 & 4.8 & 397 & 15.1 \\
\hline Mucinous & 608 & 2.8 & 87 & 3.2 & 0 & 0.0 \\
\hline Medullary & 340 & 1.6 & 29 & 1.1 & 0 & 0.0 \\
\hline Papillary & 117 & 0.5 & 24 & 0.9 & 55 & 2.1 \\
\hline Morbus Paget & 100 & 0.5 & 43 & 1.6 & 11 & 0.4 \\
\hline Cystosarcoma phyllodes & 47 & 0.2 & 1 & 0.0 & 0 & 0.0 \\
\hline Other & 4290 & & 635 & & 367 & \\
\hline All & 25,730 & & 3394 & & 2990 & \\
\hline
\end{tabular}

Percentages are for all cancers apart from those in the 'Other' category (undefined morphological types). Thus, for first primary the percentages provided are from a total of 21,440 cancers, for second primary they are from a total of 2759 cancers, and for in situ they are from a total of 2623 cancers.

\section{Results}

The Swedish Family Cancer Database covers the years 1958-1998 from the Swedish Cancer Registry, but because specific morphology has been recorded since 1993 we included only those breast cancers that were diagnosed between 1993 and 1998. Familial breast cancer was defined as those cases in which breast cancer was diagnosed in a mother or sister of the index patient during the period from 1993 to 1998.

The numbers of morphology-specific breast cancers are shown in Table 1. A total of 25,730 first and 3394 second invasive breast cancers, and 2990 in situ breast cancers were recorded during the 6-year period from 1993 to 1998 in Sweden. Ductal and lobular invasive, and in situ cancers were the most common forms; the group 'other' mainly included undefined morphological types, termed 'adenocarcinoma'. For in situ cancers some morphologies, such as tubuloductal, mucinous, medullary and cystosarcoma phyllodes, were not used. The comedo type was relatively more frequent among in situ (15.1\%) than among invasive cases $(5.6 \%)$.

Table 2 shows the distribution of morphology-specific breast cancers between mothers and daughters, diagnosed during the years 1993-1998. Only the three most common morphological types are shown separately. A total of 164 mother-daughter pairs were analyzed and a kappa value of 0.08 was calculated, indicating that the morphologies of familial cancers between two generations were entirely random. A similar analysis was carried out
Table 2

Numbers of familial breast cancers in mother and daughter by morphology

\begin{tabular}{lccccc}
\hline & \multicolumn{5}{c}{ Mother } \\
\cline { 2 - 6 } Daughter & Ductal & Lobular & Tubuloductal & Other & All \\
\hline Ductal & 52 & 8 & 6 & 36 & 102 \\
Lobular & 8 & 2 & 0 & 7 & 17 \\
Tubuloductal & 11 & 0 & 1 & 1 & 13 \\
Other & 20 & 4 & 2 & 6 & 32 \\
All & 91 & 14 & 9 & 50 & 164 \\
\hline
\end{tabular}

Kappa value for all types 0.08 .

between sisters, amounting to 100 pairs (Table 3 ). The kappa value was 0.002 , indicating that the morphology between sisters was also entirely random.

Multiple primary breast cancers were also considered (Table 4). In 907 women, two primary cancers were diagnosed. The overall kappa value was still low, at 0.22 , but there were some types that appeared to be less random. Among 147 women with first lobular cancers, 55 presented with a second lobular cancer. However, the kappa value was almost equal, at 0.23 , when only ductal and lobular morphologies were tested. Similarly, among 66 tubuloductal first cancers, 14 women were subsequently diagnosed as having a second tubuloductal cancer. The relationships between in situ and invasive breast cancer 
Table 3

\begin{tabular}{lccccc}
\multicolumn{5}{l}{ Numbers of familial breast cancers in sisters by morphology } \\
\hline & \multicolumn{5}{c}{ Sister 2} \\
\cline { 2 - 6 } Sister 1 & Ductal & Lobular & Tubuloductal & Other & All \\
\hline Ductal & 39 & 8 & 4 & 7 & 58 \\
Lobular & 6 & 2 & 1 & 4 & 13 \\
Tubuloductal & 11 & 1 & 0 & 1 & 13 \\
Other & 10 & 3 & 1 & 2 & 16 \\
All & 66 & 14 & 6 & 14 & 100 \\
\hline
\end{tabular}

Kappa value for all types 0.002 .

among 465 women are shown in Table 5. The overall kappa value was low, at 0.01 , but some combinations of in situ and invasive cancers (i.e. comedo with ductal, and lobular with tubuloductal) appeared commonly.

In Tables 4 and 5 all first and second cancers are considered irrespective of laterality or timing between the two. These variables influenced kappa values (Table 6). For the first/second invasive cancer sequence, kappa values increased when the second cancer was diagnosed in the contralateral breast (from 0.22 to 0.38 ) and marginally when it was diagnosed less than 1 year from identification of the first cancer (0.23). When both of these conditions were met, the kappa value was 0.47 , indicating moderate dependence between the morphologies. With these conditions, the kappa value was 0.63 when only ductal and lobular types were tested. The reason for these increased kappa values was that lobular tumour was often followed by another lobular tumour. Kappa was 0.40 even when ductal and lobular types were tested separately for contralateral breast cancers diagnosed more that 1 year apart. Similarly, in the in situ/invasive sequence, the kappa value was 0.33 when contralateral breasts were affected within 1 year. All of the kappa values were lower in the in situ/invasive sequence than in the first/second breast cancer sequence.

\section{Discussion}

We used the kappa test in the present analysis to test whether the morphologies of two breast cancers in family members or within the same individuals were of similar or different types [11,12]. A word of caution is in order here because the test considers the numbers of events, and common types of events are weighted more than are rare events. The ductal type, being the dominant morphology, may overshadow the patterns of rare types. Moreover, breast cancer is often of mixed morphology at presentation [3], and only the main type was recorded in the Swedish Cancer Registry. The problem of dominance can be avoided by testing individual rare types separately, but for small numbers of cases the random variation may be large. Thus, the familial cancers were so few in the present study that it was not meaningful to test separately the patterns for rare morphologies.

The data used in the present analysis were taken from the Swedish Family Cancer Database, which has almost complete nationwide coverage of families and cancer cases [7-9]. Although morphological classification has been used for only 6 years (from 1993 to 1998), the database includes information on over 25,000 first invasive and almost 3000 in situ cases.

Table 4

Numbers of breast cancers in women with first and second invasive breast cancer by morphology

\begin{tabular}{|c|c|c|c|c|c|c|c|c|c|c|}
\hline \multirow[b]{2}{*}{ 1st invasive } & \multicolumn{10}{|c|}{ 2nd invasive } \\
\hline & Ductal & Lobular & Tubuloductal & Comedo & Medullary & Mucinous & Mb Paget & Papillary & Other & All \\
\hline Ductal & 224 & 77 & 36 & 14 & 3 & 8 & 18 & 2 & 51 & 433 \\
\hline Lobular & 56 & 55 & 23 & 3 & 0 & 0 & 1 & 0 & 9 & 147 \\
\hline Tubuloductal & 25 & 17 & 14 & 2 & 0 & 2 & 0 & 1 & 5 & 66 \\
\hline Comedo & 13 & 5 & 3 & 12 & 0 & 1 & 8 & 0 & 7 & 49 \\
\hline Medullary & 4 & 1 & 0 & 5 & 0 & 1 & 0 & 0 & 1 & 12 \\
\hline Mucinous & 11 & 3 & 4 & 0 & 0 & 5 & 0 & 0 & 2 & 25 \\
\hline Morbus Paget & 5 & 2 & 0 & 1 & 1 & 0 & 0 & 0 & 1 & 10 \\
\hline Papillary & 3 & 0 & 2 & 0 & 0 & 1 & 0 & 0 & 0 & 6 \\
\hline Other & 51 & 12 & 9 & 1 & 0 & 2 & 0 & 0 & 84 & 159 \\
\hline All & 392 & 172 & 91 & 38 & 4 & 20 & 27 & 3 & 160 & 907 \\
\hline
\end{tabular}

Kappa value for all types 0.22 ; kappa value for ductal and lobular 0.23; kappa value for ductal, lobular and tubuloductal 0.18 . 
Table 5

Numbers of breast cancers in women with invasive and in situ breast cancer by morphology

\begin{tabular}{|c|c|c|c|c|c|c|c|c|c|c|}
\hline \multirow[b]{2}{*}{ In situ } & \multicolumn{10}{|c|}{ Invasive } \\
\hline & Ductal & Lobular & Tubuloductal & Comedo & Medullary & Mucinous & Morbus Paget & Papillary & Other & All \\
\hline Ductal & 77 & 37 & 44 & 7 & 2 & 15 & 9 & 3 & 13 & 207 \\
\hline Lobular & 63 & 12 & 37 & 12 & 1 & 1 & 2 & 0 & 6 & 134 \\
\hline Tubular & 0 & 0 & 0 & 0 & 0 & 0 & 0 & 0 & 1 & 1 \\
\hline Comedo & 45 & 7 & 11 & 4 & 1 & 4 & 5 & 0 & 2 & 79 \\
\hline Morbus Paget & 2 & 0 & 0 & 1 & 0 & 0 & 0 & 0 & 0 & 3 \\
\hline Papillary & 4 & 1 & 2 & 0 & 0 & 0 & 0 & 0 & 0 & 7 \\
\hline Other & 13 & 1 & 2 & 1 & 0 & 0 & 0 & 0 & 17 & 34 \\
\hline All & 204 & 58 & 96 & 25 & 4 & 20 & 16 & 3 & 39 & 465 \\
\hline
\end{tabular}

Kappa value for all types 0.01 ; kappa value for ductal and lobular 0.18 ; kappa value for ductal, lobular and tubuloductal 0.08 .

Table 6

\begin{tabular}{|c|c|c|c|c|}
\hline \multirow[b]{2}{*}{ Condition } & \multirow[b]{2}{*}{$n$} & \multicolumn{3}{|c|}{ Kappa } \\
\hline & & All types & $\begin{array}{l}\text { Ductal and } \\
\text { lobular }\end{array}$ & $\begin{array}{l}\text { Ductal, lobular and } \\
\text { tubuloductal }\end{array}$ \\
\hline \multicolumn{5}{|l|}{ 1st/2nd invasive } \\
\hline Include all & 907 & 0.22 & 0.23 & 0.18 \\
\hline Contralateral breast & 653 & 0.38 & 0.56 & 0.47 \\
\hline$<1$ year interval & 643 & 0.23 & 0.19 & 0.16 \\
\hline$\geq 1$ year interval & 264 & 0.17 & 0.30 & 0.24 \\
\hline Contralateral breast and $<1$ year interval & 416 & 0.47 & 0.63 & 0.54 \\
\hline Contralateral breast and $\geq 1$ year interval & 237 & 0.20 & 0.40 & 0.32 \\
\hline \multicolumn{5}{|l|}{ In situ/invasive } \\
\hline Include all & 465 & 0.01 & 0.18 & 0.08 \\
\hline Contralateral breast & 153 & 0.21 & 0.21 & 0.17 \\
\hline$<1$ year interval & 359 & 0.06 & 0.28 & 0.14 \\
\hline$\geq 1$ year interval & 106 & 0.15 & 0.25 & 0.22 \\
\hline Contralateral breast and $<1$ year interval & 93 & 0.33 & 0.27 & 0.21 \\
\hline Contralateral breast and $\geq 1$ year interval & 60 & 0.02 & 0.13 & 0.12 \\
\hline
\end{tabular}

The main finding of the present study is that the morphological types of breast cancer are not genetically determined. The kappa values were close to 0 for morphology-specific familial breast cancers, analyzed in mother-daughter or sister-sister pairs. Such analyses are most convincing because the presentation of morphology is completely independent. Even the morphological presentation of first and second breast cancers, and in situ and invasive breast cancers were almost completely random when restricted to contralateral cancers diagnosed more than 1 year apart. Such conditions are likely to define two independent primary tumours. The only exception was when ductal and lobular cancers were tested separately, for which the kappa value was 0.40 .

The only observations that suggest a nonrandom presentation were confined to contralateral invasive tumours, diagnosed less than 1 year apart. The kappa value was 
0.47 when all tumour types were tested and 0.63 when testing was confined to ductal and lobular types. These high kappa values were accounted for by lobular tumours. Lobular in situ or invasive breast cancer is often multifocal or bilateral at presentation, and even if unilateral this morphology has a tendency to predispose to cancer in the contralateral breast $[3,13]$. The high kappa values for tumours diagnosed less than 1 year apart suggest that the second cancer is not independent from the first one, and that it may be a recurring tumour. It may seem paradoxical that an increased kappa was found only for contralateral tumours diagnosed less than 1 year apart. The probable explanation lies in the instructions in the Swedish Cancer Registry regarding the reporting of multiple primary tumours. Tumours that are diagnosed temporally close together are likely to be reported as independent primaries if they occur contralaterally rather than ipsilaterally. Because practically all tumours reported to the Swedish Cancer Registry are histologically or cytologically verified, the reliability of the data is high, and this also applies to second primaries [14].

In summary, within the limits of the present sample size, the results suggest that morphological types of breast cancer are not genetically determined.

\section{Acknowledgements}

The Swedish Family Cancer Database was created by linking registers maintained at Statistics Sweden and the Swedish Cancer Registry. The study was supported by the Swedish Cancer Society and the King Gustaf V Jubilee Fund.

\section{References}

1. Russo J, Russo I: Cellular basis of breast cancer susceptibility. Oncol Res 1999, 11:169-178.

2. Kumar V, Cotran R, Robbins S: Basic Pathology. Philadelphia: W.B. Saunders; 1997.

3. Harris J, Morrow M, Bonadonna G: Cancer of the breast. In Cancer: Principles \& Practice of Oncology, vol 4. Edited by DeVita V Jr, Hellman S, Rosenberg S. Philadelphia: J B Lippcott; 1993:1264-1332.

4. Lakhani SR, Gusterson BA, Jacquemier J, Sloane JP, Anderson TJ, van de Vijver MJ, Venter D, Freeman A, Antoniou A, McGuffog L, Smyth E, Steel CM, Haites N, Scott RJ, Goldgar D, Neuhausen S, Daly PA, Ormiston W, McManus R, Scherneck S, Ponder BA, Futreal PA, Peto J, Stoppa-Lyonnet D, Bignon YJ, Stratton MR: The pathology of familial breast cancer: histological features of cancers in families not attributable to mutations in BRCA1 or BRCA2. Clin Cancer Res 2000, 6:782-789.

5. Lakhani SR, Jacquemier J, Sloane JP, Gusterson BA, Anderson TJ, van de Vijver MJ, Farid LM, Venter D, Antoniou A, Storfer-Isser A, Smyth E, Steel CM, Haites N, Scott RJ, Goldgar D, Neuhausen S, Daly PA, Ormiston W, McManus R, Scherneck S, Ponder BA, Ford D, Peto J, Stoppa-Lyonnet D, Easton DF: Multifactorial analysis of differences between sporadic breast cancers and cancers involving BRCA1 and BRCA2 mutations. J Nat/ Cancer Inst 1998, 90:1138-1145

6. Lei H, Sjöberg-Margolin S, Salahshor S, Werelius B, Jandakova E, Hemminki K, Lindblom A, Vorechovsky I: CDH1 mutations are present in both ductal and lobular breast cancer, but promoter allelic variants show no detectable breast cancer risk. Int J Cancer 2002, 98:199-205.

7. Hemminki K, Li X, Plna K, Granström C, Vaittinen P: The nationwide Swedish Family-Cancer Database: updated structure and familial rates. Acta Oncol 2001, 40:772-777.

8. Hemminki K: Genetic epidemiology: science and ethics on familial cancers. Acta Oncol 2001, 40:439-444.
9. Hemminki K, Li X: Familial carcinoid tumors and subsequent cancers: a nation-wide epidemiological study from Sweden. Int J Cancer 2001, 94:444-448.

10. Centre for Epidemiology: Cancer Incidence in Sweden 1998. Stockholm, Sweden: Centre for Epidemiology; 2000.

11. Armitage P, Berry G: Statistical Methods in Medical Research, 3rd ed. Oxford: Blackwell; 1994.

12. dos Santos Silva I: Cancer Epidemiology: Principles and Methods. Lyon: IARC; 1999.

13. Chen Y, Thompson W, Semenciw R, Mao Y: Epidemiology of contralateral breast cancer. Cancer Epidemiol Biomarkers Prev 1999, 8:855-861.

14. Frödin J-E, Ericsson J, Barlow L: Multiple primary malignant tumors in a national cancer registry. Reliability of reporting. Acta Oncol 1997, 36:465-469. 